\title{
VIRTUAL 3D CITY MODELING: TECHNIQUES AND APPLICATIONS
}

\author{
Surendra Pal Singh $^{1 a^{*}}$, Kamal Jain ${ }^{1 b}$, V. Ravibabu Mandla ${ }^{2}$ \\ ${ }^{1 a}$ Geomatics Engineering Section, Department of Civil Engineering, Indian Institute of Technology, Roorkee, \\ (Roorkee), India. Corresponding author ${ }^{1 a^{*}}$ Email- (surendra.geomatics@ gmail.com), \\ ${ }^{1 b}$ Geomatics Engineering Section, Department of Civil Engineering, Indian Institute of Technology, Roorkee, \\ (Roorkee), India. ${ }^{1 b}$ E-mail (kjainfce@iitr.ernet.in) \\ ${ }^{2}$ School of Mechanical and Building Sciences, Vellore Institute of Technology(VIT)-University,Vellore, Tamilnadu, \\ India. E-mail (ravi.mandla@ vit.ac.in)
}

\section{Commission II, WG II/2}

KEY WORDS: Virtual 3-D City, Geomatics Techniques, Laser Scanning, Close Range Photogrammetry, Level of Detail.

\section{ABSTRACT:}

3D city model is a digital representation of the Earth's surface and it's related objects such as Building, Tree, Vegetation, and some manmade feature belonging to urban area. There are various terms used for 3D city models such as "Cybertown", "Cybercity", "Virtual City", or "Digital City". 3D city models are basically a computerized or digital model of a city contains the graphic representation of buildings and other objects in 2.5 or $3 \mathrm{D}$.

Generally three main Geomatics approach are using for Virtual 3-D City models generation, in first approach, researcher are using Conventional techniques such as Vector Map data, DEM, Aerial images, second approach are based on High resolution satellite images with LASER scanning, In third method, many researcher are using Terrestrial images by using Close Range Photogrammetry with DSM \& Texture mapping.

We start this paper from the introduction of various Geomatics techniques for 3D City modeling. These techniques divided in to two main categories: one is based on Automation (Automatic, Semi-automatic and Manual methods), and another is Based on Data input techniques (one is Photogrammetry, another is Laser Techniques). After details study of this, finally in short, we are trying to give the conclusions of this study. In the last, we are trying to give the conclusions of this research paper and also giving a short view for justification and analysis, and present trend for 3D City modeling.

This paper gives an overview about the Techniques related with "Generation of Virtual 3-D City models using Geomatics Techniques" and the Applications of Virtual 3D City models. Photogrammetry, (Close range, Aerial, Satellite), Lasergrammetry, GPS, or combination of these modern Geomatics techniques play a major role to create a virtual 3-D City model. Each and every techniques and method has some advantages and some drawbacks. Point cloud model is a modern trend for virtual 3-D city model. Photo-realistic, Scalable, Geo-referenced virtual 3-D City model is a very useful for various kinds of applications such as for planning in Navigation, Tourism, Disasters Management, Transportations, Municipality, Urban Environmental Managements and Real-estate industry. So the Construction of Virtual 3-D city models is a most interesting research topic in recent years. 


\section{INTRODUCTION:}

Now a day's 3-D City modeling is an important issue in all over the world for Geomatics researcher. Geomatics techniques are playing a key role to create virtual 3D City model. Geomatics is an umbrella term for the mapping technologies. Main Geomatics techniques are Photogrammetry, Remote sensing, Geographical Information System, Global Positioning System, Lasergrammetry, and Radargrammetry etc. Photogrammetry and Laser techniques play a major role to create Virtual 3-D City modeling. So many Geomatics researchers are working in this direction. Till now, there is no systematic literature review is available on $3 \mathrm{D}$ City modeling by using Geomatics techniques, specially based on techniques and applications. This Literature review is very essential and useful for all Geomatics researcher working for 3D City modeling, because this review paper explains about the techniques available for $3 \mathrm{D}$ City modeling with advantages and limitations. This review paper also gives a summary of applications of 3D City models used by various researchers for various applications. This paper will explain most of the representative Geomatics techniques for 3D City modeling and the main work for each category with method. This paper also gives a brief summary for all possible applications of virtual 3D City model that explain by various researchers. So this paper will be very useful for Geomatics researchers who are working for Virtual 3D City model generation by using Geomatics techniques. By using this paper, they can easily understand the various techniques, methods, advantages, limitations used by various researchers. They can also understand about various applications of 3D City models. In present scenario, for 3D City modeling, the study of available Geomatics techniques is very important due to advantages and limitation of each technique. Project Time, Project Cost, Accuracy and texturing are very important factor for 3D City modeling, which mainly depends on user requirements. So we choose the main two criteria (Techniques and Applications of 3D City models) for study of literature review. The main aim of this research paper is to provide a Literature review on Virtual 3D City modeling by using Geomatics techniques with special focus on Techniques and Applications. In this paper, first explain about techniques and methods to create virtual 3D City model by many researchers from all over the world. There are many methods available to create Virtual 3D City models and researchers are trying to develop efficient and effective methods. In this study, we try to collect research paper related with work, but these all papers may not be very sufficient. We try to add at least minimum one or more than one research paper for each techniques and methods. We also try to summarize the work related with Applications of 3D City model based on previous study by various researchers. In my view some researchers work may be missed in this paper. We start this paper from the introduction of various Geomatics techniques for 3D City modeling. These techniques divided in to two main categories: one is based on Automation (Automatic, Semi-automatic and Manual methods), and another is Based on Data input techniques (one is Photogrammetry, another is Laser Techniques). After details and short study of this, finally we are trying to give the conclusions of this study. In the last, we are also giving a short view for justification and analysis, and present trend for 3D City modeling.

\section{GEOMATICS TECHNIQUES AND METHODS FOR 3D CITY MODELING:}

These 3D modeling methods are mainly categorized in to the following approaches:

\section{Based on Automation- \\ $>$ Automatic \\ $>$ Semi-automatic \\ $>$ Manual}

\section{Based on Data input techniques-}

Photogrammetry based methods

Laser Scanning based methods

\section{Photogrammetry based methods for 3-D City Model generation: \\ Aerial Photogrammetry based model \\ $>$ Satellite Photogrammetry based model \\ $>$ Close Range Photogrammetry based model}

\section{LASER scanning based model-}

Aerial Laser based model

$>$ Terrestrial laser based model

\section{HYBRID METHODS:}

Combination of these methods is also a method to create virtual 3-D City model.

\section{PHOTOGRAMMETRY Based 3-D City Models}

\section{Aerial Photogrammetry based model:}

Now a day, mostly airborne data is using for the collection of $3 \mathrm{D}$ city models. Aerial photos are the most commonly using as a raw data. Stereo pair images are useful to create the 3D point cloud.

A semi-automatic method for acquiring 3D topologically structured data from $2 \mathrm{D}$ aerial stereo images has been presented by Sisi Zlatanova. (Zlatanova et al., 1998). 
In this work, they used a digital photogrammetric workstation (Traster T10), Microstation CAD package, and Consob, (in-house developed software); they used Digital aerial images of scale 1:2200 for Enschede (Netherlands). Data Acquisition, Data Processing, Superimposition, Database Updating, and Visualisation are the main steps for this work.

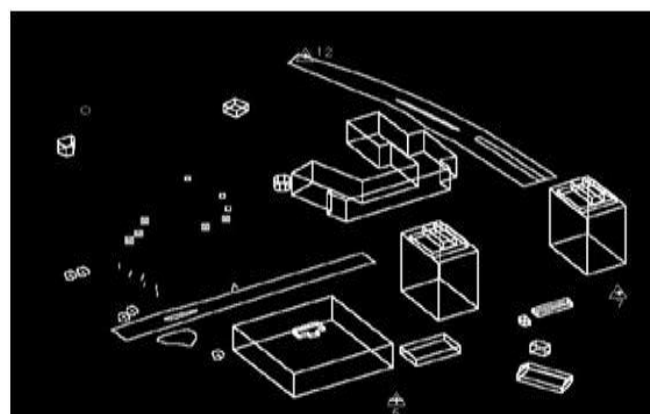

Fig.1- Reconstructed 3D objects and Buildings (S.Zlatanova, et al., 1998)

They classified the objects (Roofs) as various classes such as No Longitudinal breaks (flat roof), two facades roof, three facade roof, Roof composite etc. This was very basic and primitive model for 3D City.

Kobayashi (2006), studies about relation with Photogrammetry and 3D City modeling. $\mathrm{He}$ recommends a methodology to create 3D City model by using Photogrammetric processing. He also used aerial images to create $3 \mathrm{D}$ city model with Photogrammetry techniques and discusses the efficiency and effectiveness of the model in terms of time, labor, and reusability. In this work, he make the 3D city model of Phoenix, USA.

Shashi and Jain (2007), explore the use of Photogrammetry for 3D modeling and scene visualization. They suggested and give an approach to create $3 \mathrm{D}$ model of any building by using normal digital camera and close range photogrammetric processing for any project with good accuracy. The main advantages of this work were, Digital cameras are easily available in market in low cost. They concluded that Close range Photogrammetry gives the best solution for $3 \mathrm{D}$ modeling.

Lebrel et al., (2010), investigates the difference between Point cloud generated from Images and Point cloud generated from Laser. They discuss that the photogrammetric accuracy is good with compare to the lidar-method, and also the density of surface points is much higher from images. They also found some additional advantages of the photogrammetric approach.

Cristina et al., (2010), studies about augmented reality and Photogrammetry. Close range Photogrammetry creates Photo-realistic 3D model. This model exported into other software for Virtual reality. The sound, text and video data can be added in this work. So this environment is useful for navigation with good visual interaction on different platforms like Desktop PC, Laptop, and mobile phones. Augmented Reality (AR) is also a technique, in which real and virtual environment can be mixed that is very useful for human interaction and real life navigation. So they suggest that the combination of Augmented Reality and Photogrammetry opens up new possibilities in the field of 3D data visualization, navigation. In this work, they introduce a low-cost outdoor mobile AR application to integrate buildings of different urban spaces. This work shows the real-time orientation and tracking in combined physical and virtual city environments, by merging close-range photogrammetry and AR.

Amat et al., (2010), investigates a methodology to create virtual 3-D City model by using the combination of Aerial Photogrammetry and Close range Photogrammetry. In this method, they suggest that, small 3D buildings, window, door, are not visible in aerial images, so CRP used to create photo-realistic virtual model of small building and large buildings with roof structure created with stereo-images from aerial data. So with the help of combination of these Close range photogrammetric and aerial Photogrammetry techniques, Photo-realistic Virtual 3D city model created.

Hammoudi and Dornaika (2011), also gives an approach for reconstructing 3D polyhedral building models from aerial images. Geometric and Photometric properties used with perspective projection of planar structures. The advantage of this method is in its featurelessness and in its use of direct optimization based on image raw brightness. They avoid feature extraction and matching. They estimated 3D polyhedral model directly by optimizing an objective function that combines an image-based dissimilarity measure and a gradient score over several aerial images. The Differential Evolution algorithm used for the optimization process. In this approach, they provide more accurate 3D reconstruction than feature-based approaches. Fast updating and fast 3D model rectification are the main advantage for this approach. They also tested this method for various images.

\section{D City model by Aerial Images and Cadastral Map:}

Flamanc et al., (2003) create buildings reconstruction framework for 3D city models production by using aerial images and cadastral maps. They tested model driven and the data driven approaches.

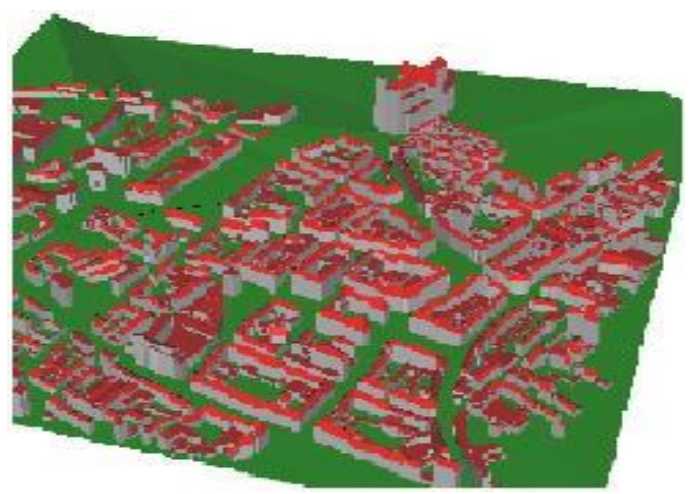

Fig.2. 3D City model (Source- Flamanc et al., 2003) 


\section{D City model by Computer Vision Techniques:}

Lang and Forstner, (1996), describe a semi-automatic system for acquiring the $3 \mathrm{D}$ shape of buildings as topographic objects.

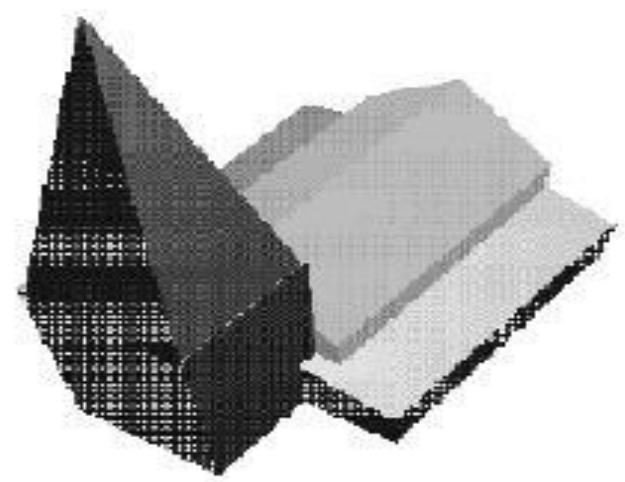

Fig.3- 3D Building model from one eye stereo camera (Lang and Forstner-1996)

Pollefeys et al., (2000) gives a methodology to create automated reconstruction of good textured 3D model from images sequences. The main advantage of this work is that, without camera parameters information, 3D model generated. This system is based on computer vision algorithms. In this method, the accuracy is not very good for metrology application, but due to photo-realistic texturing, visual quality is very convincing. So this system is useful for various applications in Archeology. They tested this approach for the Roman site of Sagalassos southwest Turkey.

Jang and Jung, (2006), create 3D City Model from Ground Images. Digital camera is used for ground images of a area, This camera is mounted with GPS and digital compass. The advantage of this method is that it can handle a huge number of images. They used an algorithm based on Structure from Motion (SFM) to correct their poses; they also used a method of global pose estimation that can register $3 \mathrm{D}$ isolated building models in a global coordinate system. This system is based on SFM and presented for large-scale 3-D City modeling.

Jürgen Döllner et al., (2006), create Virtual 3D City model of Berlin. In this project they developed a system for integrating, managing, presenting, and distributing complex urban geoinformation. Virtual $3 \mathrm{D}$ city models, therefore, constitute a major concept in 3D geoinformation systems (3D GIS). In this projects Digital Aerials Photos, DTM, Geo-referenced thematic data, 3D Geodata, Digital Architecture models, and Cadastral data used as input and 3-D Geodata base System and Virtual 3-D City model comes as output products.

Cornelis et al., (2007), investigates about 3D Urban Scene Modeling Integrating Recognition and Reconstruction. In this proposed system, the input data are two video streams, recorded by a calibrated stereo rig mounted on top of a survey vehicle with GPS/INS measurements. They used these stereo camera pairs and by Real time Structure from Motion (SfM) concept and also used object detection techniques. The beauty of this work was; they create Real time 3-D reconstruction for a 3-D City model

Snavely Noah et al., (2008), proposed a new method for modeling the world from internet photo collections. They introduced a concept of Photo-Tourism. They proposed an approach to create 3D model of any building or site by using unordered collection of photographs downloaded from internet. In this project they used the concept of structure-from-motion and image-based rendering algorithms. They tested this approach for Google image search for "Notre Dame"(Paris), Mount Rushmore, a set of photos of Mount Rushmore National Monument, South Dakota, Trafalgar Square (London), Half dome in Yosemite National park, Trevi Fountain (Rome), Sphinx, (Giza), St. Basil's Cathedral (Moscow), Colosseum in Rome and also Great Wall of China.

Jianxiong Xiao et al., (2009), proposed an automatic approach to generate street-side 3D photo-realistic models from images captured along the streets at ground level. They propose an inverse patch-based orthographic composition and structure analysis method for facade modeling that efficiently regularizes the noisy and missing reconstructed 3D data. The main drawback of this method was; the upper parts of large buildings are not modeled due to the limited viewing field of a ground-based camera.

\section{D City models by GIS:}

Gruen A. and Xinhua W., (1999), developed a powerful system CyberCity Modeler (CC-Modeler). CyberCity-Modeler (CC-Modeler) is a methodology and software for the automatic generation of the topology of an unstructured 3-D point cloud. It has been developed in order to generate structured data for city modeling from photogrammetrically measured points. It is specially designed for the handling of 3-D city data, and the integration of raster images and vector data in terms of a hybrid GIS.

Nedal Al-Hanbali et al., (2006) work for 3D GIS model for Jerash City and Artemis temple. They use the Photogrammetric principles and GIS method to create this model. The main aim of this work was to build a 3D virtual reality model of the Artemis Temple, and to construct a GIS model of the Jerash City. These are the 3D GIS model and useful for very accurate measurements and detailed texture, which can allow visualization, preservation and reconstruction of the temple with City. This work is planned to be carried out from macro level, i.e. the modeling of the modem and ancient city via 3D GIS, to micro level, i.e. building 3D virtual models as well as 3D GIS databases for each monument.

Nedal Al-Hanbali et al., (2006) makes a three dimensional Model for Yarmouk University by using GIS and Photogrammetry techniques. 


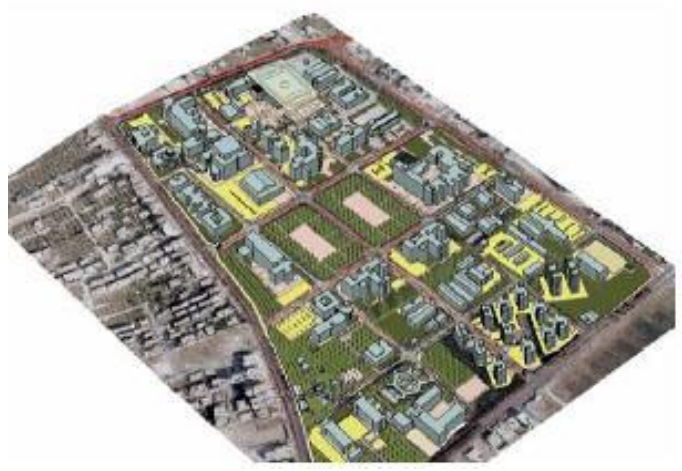

Fig.4- 3-D Model for Yarmouk University (source: Al-Hanbali et al., 2006)

Malumpong C., and Chen X., (2008), used the interoperable 3-D GIS City Modeling with GIS and 3-D Modeling software. Google SketchUp Pro is used for reconstruction of buildings. This work aims to describe the integration of geo-informatics techniques with 3D modeling software to develop 3-D GIS database which includes reconstruction of buildings, terrain, and other features that are relevant to a city model.

Zhou Li et al., (2008), studied the 3-D GIS based techniques and Digital Photogrammetry.

This work discusses the object-oriented 3D modeling technique to use existing digital photogrammetry software platform for secondary development.

Razzak A. et al., (2009), work for 3-D Virtual Maps Production for Mosul City by using GIS Techniques. He follows the Virtual GIS methodology for his work. The final 3D digital map contains all necessary information for users and designers to reach to the best decision.

Thompson and Horne, (2009), work for Virtual NewcastleGateshead (VNG) project and focus mainly on issues relating to data exchange, CityGML, data accessibility and interoperability in piloting Autodesk LandXplorer.

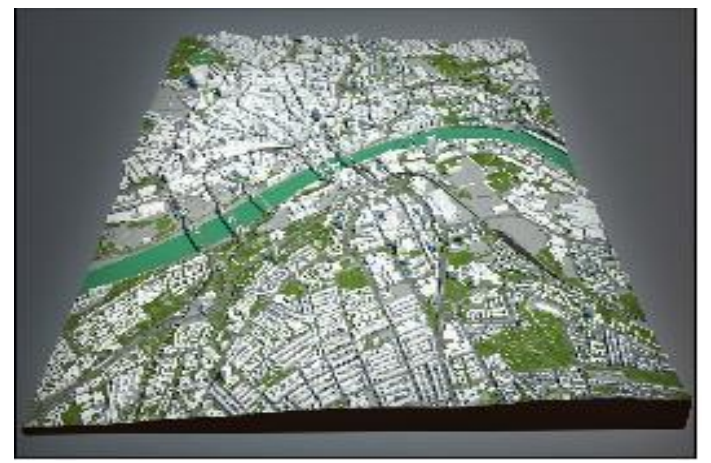

Fig.5- VNG Model extents. (Context Model (C) Zmapping Ltd., 2009.)

\section{D City from Satellite Photogrammetry:}

Tao and Yong $\mathrm{Hu}$, (2002), evaluated a concept of Rational Function Model (RFM) for 3D Reconstruction. Due to RFM parameters the Orthorectification, 3D reconstruction, and DEM generation is possible without the physical sensor model. In this study, they investigate two methods for RFM-based 3D reconstruction, the inverse RFM method and the forward RFM method. They concluded that the forward RFM can achieve better reconstruction accuracy. Finally, real Ikonos stereo pairs were used to verify the applicability and the performance of the 3D reconstruction method.

Fraser et al., (2002), investigates with Ikonos imagery for sub metre 3D positioning and building extraction. A quantitative and qualitative assessment done by using stereo Ikonos imagery for generating building models, for the campus of the University of Melbourne.

Kocaman et al., (2006), tested a methodology for 3-D City modeling from high resolution satellite images with the help of software called SAT-PP, (Satellite Image Precision Processing) and CyberCity Modeler software. They tested the potential of SAT-PP and CyberCity Modeler to extract DSMs and buildings, and to produce 3D city models with IKONOS and Quickbird stereo images.

Tack et al., (2009), developed and tested a methodology for semi automatic city model extraction from tri-stereoscopic very high resolution satellite imagery. They studied the IKONOS triplet data for city Istanbul, Turkey with photogrammetric software platform, called SAT-PP, (Satellite Image Precision Processing).

\section{D City model from Single Satellite Image:}

Poul et al., (2006), also tested a method to create a digital city models using single high resolution satellite. They used Quickbird image of Abu dhabi (UAE) area.

Huang et al., (2008), proposed a method for objects reconstruction from single high-resolution satellite image using Monoplotting technique.

They used Rational Polynomial Coefficients (RPC), and high resolution of Digital Elevation Models (DEM) to achieve the high precision geometry of the 3D reconstructed object. The ray of the satellite determines from RPC and shadow of the object on the ground, determine from the Azimuth and elevation angles of the sun. The vertices of the polygon, manually extracted from top of the surface of an object, are used for the prediction of the base and shadow positions on the 2D satellite image based on the height of the object. The height of the object is determined from predicted base and shadow positions match their position in the image by observation. They tested this method on IKONOS image and also developed software for real-time extracting, editing, reconstructing and visualizing of the $3 \mathrm{D}$ objects from single IKONOS image. 
Izadi, and Saeedi, (2012), investigate a method for Three-Dimensional Polygonal Building Model from Single Satellite Images. They developed a methodology of a system for automatic detection and height estimation of buildings with polygonal shape roofs in single satellite images. The proposed system includes two main parts: 2-D Rooftop Detection and 3-D Building Estimation. This system is capable of detecting multiple flat polygonal buildings with no angular constraints or shape priors. In this project, they verify the effectiveness of the presented system with overall mean shape accuracy of $94 \%$ and mean height error of $0.53 \mathrm{~m}$ on QuickBird satellite $(0.6 \mathrm{~m} / \mathrm{pixel})$ imageries.

\section{D City from Panorama Photogrammetry:}

Luhmann, and Tecklenburg, (2004), discuss about 3-D Object reconstruction from multiple-station panorama imagery. They describe about image acquisition, panorama generation by frame imagery and by rotating line-scanner imagery, calibration, tie point and control point measurement, panorama bundle adjustment to the final image compilation of 3-D objects.

They suggested that, due to the stable geometry of the cylindrical panorama model the bundle adjustment can be performed with very few object points. Once each panorama is oriented with respect to global coordinate system, then photogrammetric object reconstruction procedures such as space intersection or a moving floating mark can be applied and finally 3-D model created. In this study, they tested this work for entrance hall of the university as 3-D wireframe model of the interior and Great Hall of the Oldenburg castle. They created four panoramas and processed to produce a high-quality color panorama.

Fangi G., (2009), and Pisa, Zeppa and Fangi, (2010), also recommend the importance of Spherical Photogrammetry for 3D cultural heritage. They tested and suggested that, Spherical-Panorama techniques are also useful to create virtual 3-D model.

Micusı, and Kosecka, (2009), also give a methodology for Piecewise Planar City 3D Modeling from Street View Panoramic Sequences.

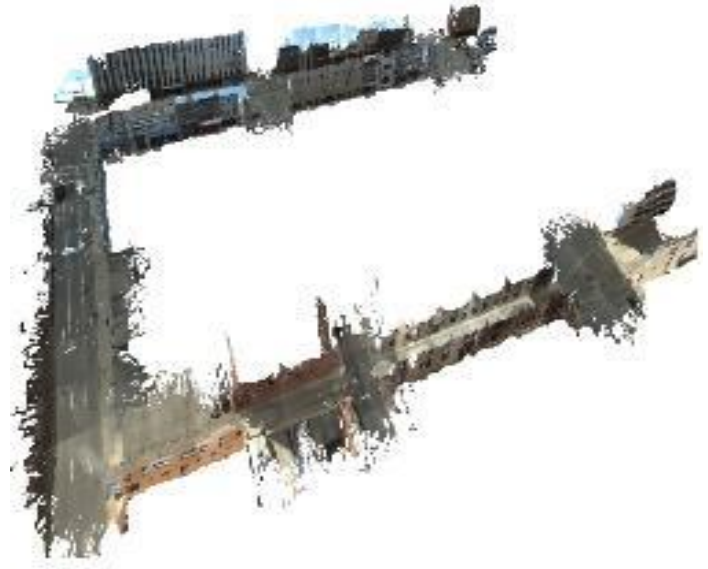

Fig.6- City model reconstruction from car image sequences (Source-Micusık,\& Kosecka, 2009).

\section{D City Models from Video:}

For 3-D city modeling, Video is an easy obtainable and low cost data so now a day, many researchers interest is increasing.

Videogrammetry is a measurement technique which is mainly based on the principles of 'Photogrammetry, (Gruin A.,1997). Videogrammetry refers to video images taken using camcorder or movie function on digital still camera. Video movie consists of sequences of images (or frames). If video speed is $25 \mathrm{fps}$ (frame per second) and taken for 1 minute (i.e. 60 seconds), there are 25 frame per second or overall 1500 image.

Some of the important works are listed here-

Clip et al., (2008), designed a Mobile 3-D City Reconstruction system. It is an efficient flexible capture and reconstruction system for the automatic reconstruction of large scale urban scenes. This system is both backpack and vehicle mounted allowing the capture of interior or less accessible areas as well as large outdoor scenes.

In this work, they propose an efficient capture system to capture the 3D-geometry of existing cities through computer vision techniques. This system is able to deliver 3D reconstructions of large urban scenes with near real time. This system is modular and man portable, it is able to record both from a backpack mounting for interior areas and from an automobile for exterior recording. GPS and INS also used in this product.

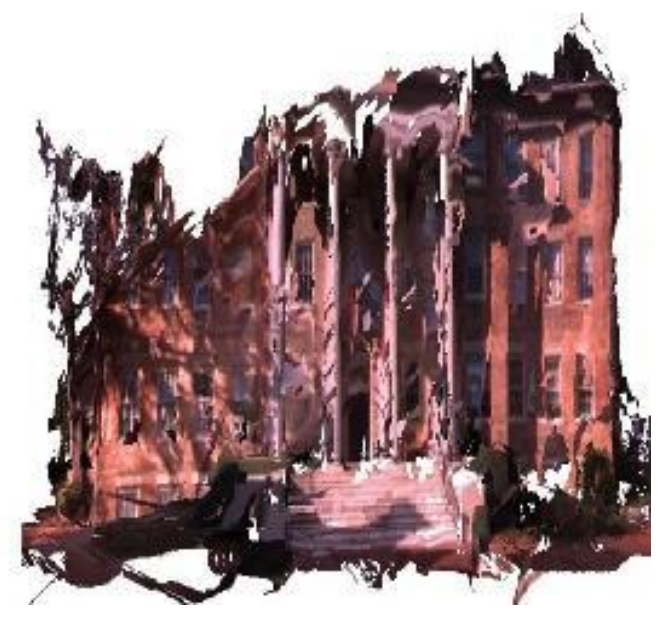

Fig.7- 3D reconstruction from Video only with the back pack system

Zhao et al., (2005), gives a concept of Alignment of Continuous Video onto 3D Point Clouds. They work on video data and Lidar data and propose a general framework for aligning continuous (oblique) video onto 3D sensor data. They align a point cloud computed from the video onto the point cloud directly obtained from a 3D sensor. The capability to align video before a 3D model is built from the 3D sensor data offers new practical opportunities for 3D modeling. They introduce a novel modeling-through- 
registration approach that fuses $3 \mathrm{D}$ information from both the 3D sensor and the video.

Fulton and Fraser, (2009), explained a method for automatic reconstruction of building by using a hand held video camera. In this method, a video recording takes of a building of interest. Video sequence transferred into computer and saved as individual JPEG Frames. Blurred frames remove and Non-blurred key frames selected and registered these Non-blurred key frames by using Phase correlation method, and after this feature extraction done.

Colleu et al., (2008), gives a method for Automatic Initialization for the registration of GIS and Video data. The main aim of this work is to automatically compute the initial registration of a GIS model and a video sequence. In this method a coarse registration is obtained using GPS data and the theory of epipolar geometry. Then, a simultaneous pose and correspondence determination is done and RANSAC algorithm applied on line features.

In Japan, Kawasaki et al., (1999), also work for Automatic Modeling of a 3D City Map from RealWorld Video. They proposed a efficient method for making a 3D map from real-world video data. The proposed method is an automatic organization method by collating the real-world video data with map information using DP matching.

They also made a system which can generate a $3 \mathrm{D}$ virtual map automatically with a VRML form.

Zhang et al., (2009), gives a concept for Consistent Depth Maps Recovery from a Video Sequence. Video Image sequence frame used and created Depth maps from these frames.
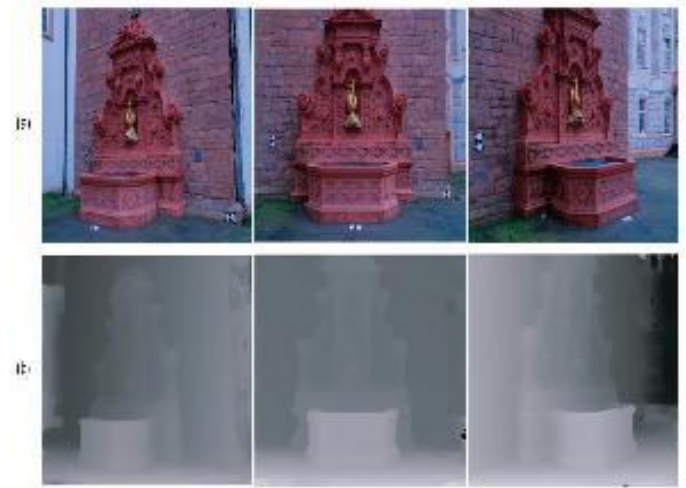

Fig.8- (a) Frames 2, 5, and 8. (b) The estimated depth maps

In this method, they used the Structure From Motion (SFM) to recover the camera parameters, Disparity Initialization, Bundle optimization, and Space-Time fusion techniques to create depth maps. These depth maps are very useful to create virtual 3-D model of an area or object.

In 2008, M. Pollefeys and his team create a detailed real time urban reconstruction from Video. They used Video data and GPS/GNS data. In this method, there are two main processing components. One is for Video data input and another is Computing component. After video data input, the data reading or data preparation is a processing component.

In computing component, 2-D tracker (GPU) and 3-D tracker/Geo-location are the main track. Geo-located camera used in this process. By using Sparse scene analysis and Multi-View stereo, Depth map is generated which is very useful to create 3 -d model of a area. After this Triangular mesh texture map generated which give a Photorealistic textured 3-D model of that area.

Some of the results are showing as given below from this work-

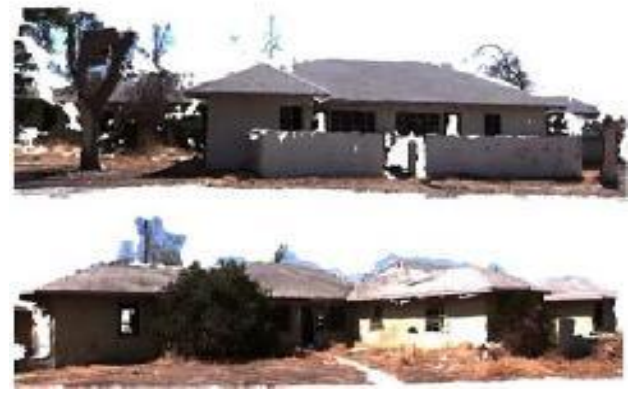

Fig.9 - Reconstructions of scene.

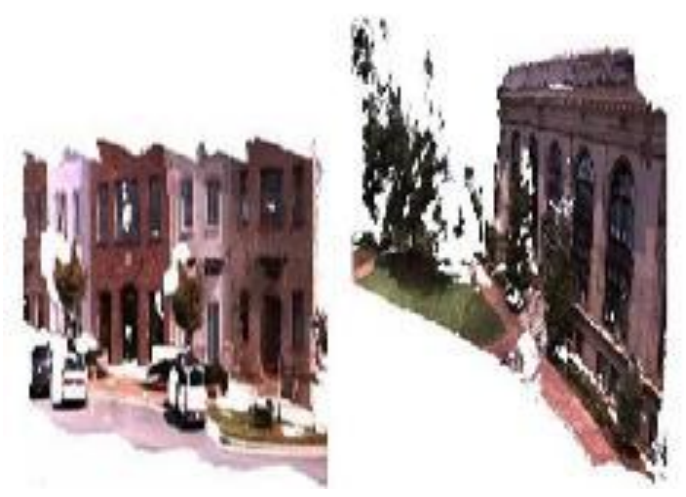

Fig.10- Reconstructed models from video

Jose et al., (2001), developed an algorithm for Epipolar frames in a Line for Videogrammetry.

Gael et al., (2007), explained a system for computing geo-referenced positions and orientations for non calibrated videos images of buildings. This method is based on the fusion of multimodal datasets, namely GPS measures, video sequences and rough 3D models of buildings. This is a method for registration of GPS, GIS, and Video data for urban scene modeling.

Tian et al., (2010), gives a concept of Knowledgebased building reconstruction from terrestrial video sequence. They give an automatic method for the reconstruction of building models from video image sequences. Building structure knowledge is used as a key factor.

In this work, the results show that this method correctly sets up topological relationships between generated surface patches and also obtains reasonable 
structure models in occluded areas. Therefore, the reconstructed models satisfy requirements for both visualization and analysis.

Tsai et al., (2006), develop a method for Texture Generation and Mapping by using Video Sequences for 3D Building Models.

Pollefeys et al., gives a method for 3-D model generation by using Video image sequence. This method is a fast method to create a $3 \mathrm{D}$ city model.

Hengel et al., (2007), developed a method and system, (named as Video Trace). VideoTrace is a system for interactively generating realistic $3 \mathrm{D}$ models of objects from video. The combination of automated and manual reconstruction allows VideoTrace to model parts of the scene not visible, and to succeed in cases where purely automated approaches would fail.

In this system initially a frame from the input video sequence takes and a partial tracing of the model takes place then the final model overlaid on the video, and the result of rendering the final model back into the original sequence.

\section{D City Modeling with TLS data:}

Gruen, et al., (2003), tested the Three-Line Scanner system data to create Virtual 3-D City model. The TLS (Three-Line-Scanner) system is an aerial camera system developed by STARLABO, in year 2000 in Tokyo (Japan). They produced high resolution phototextured models of Yokohama with CyberCity Modeler software.

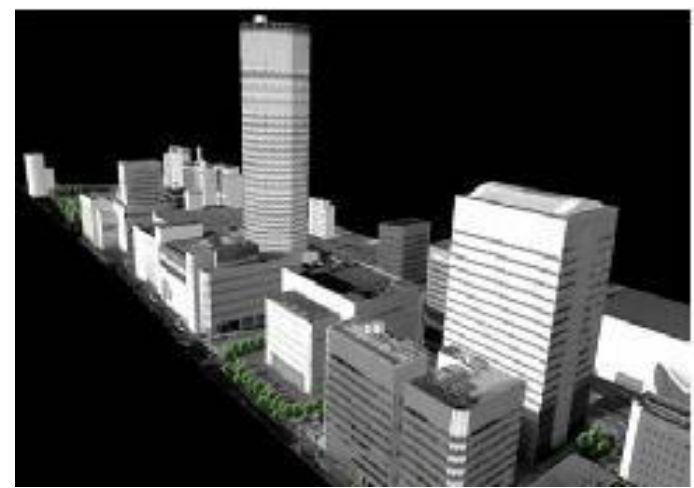

Fig.11. 3-D textured model of Yokohama City

\section{D City by Unmanned Aerial Vehicle (UAV):}

Puschel et al., (2008), tested Unmanned Aerial Vehicle (UAV) images with terrestrial images to create 3-D Model of castle Landenberg by using close range photogrammetric processing.

Eugster and Nebiker, (2009), studies about Real time Geo-registration of video stream from mini or micro UAS using Digital 3-D City models, The micro and mini UAS (Unmanned Aircraft System) systems are low cost system and equipped with light weight data acquisition sensors like video cameras. These systems have real-time data transmission capability with lowquality INS/GNSS sensors for position and attitude control. In this study, they evaluated fully automated video imagery geo-registration approaches.

\section{LASER Based 3-D City Models:}

Vosselman and Dijkman, (2001), recommend a methodology and algorithm for 3D building model reconstruction from point clouds and ground plan. They used the well-known Hough transform for the extraction of planar faces from the irregularly distributed point clouds. They explored two different strategies to reconstruct building models from the detected planar faces and segmented ground plans.

Dorninger and Pfeifer, (2008), proposed a comprehensive approach for automated determination of $3 \mathrm{D}$ city models from airborne acquired point cloud data. They used a comprehensive automated 3D Approach for Building Extraction, Reconstruction, and Regularization from Airborne Laser Scanning Point Clouds. This work is based on the assumption that individual buildings can be modeled properly by a composition of a set of planar faces. So this work is based on a reliable 3D segmentation algorithm, detecting planar faces in a point cloud.

Ming et al., (2009), Investigates and proposed the methodology and algorithms for automatic Generation of Three Dimensional Photo-Realistic Models from Lidar and Image Data. They implemented automatic 3D point cloud registration, automatic target recognition that is used for geo-referencing and automatic plane detection algorithm that is used for surface modeling, and texture mapping. They proposed a approach, that is useful to create the accurate and georeferenced 3-Dimentional photo-realistic models from point clouds and digital imagery.

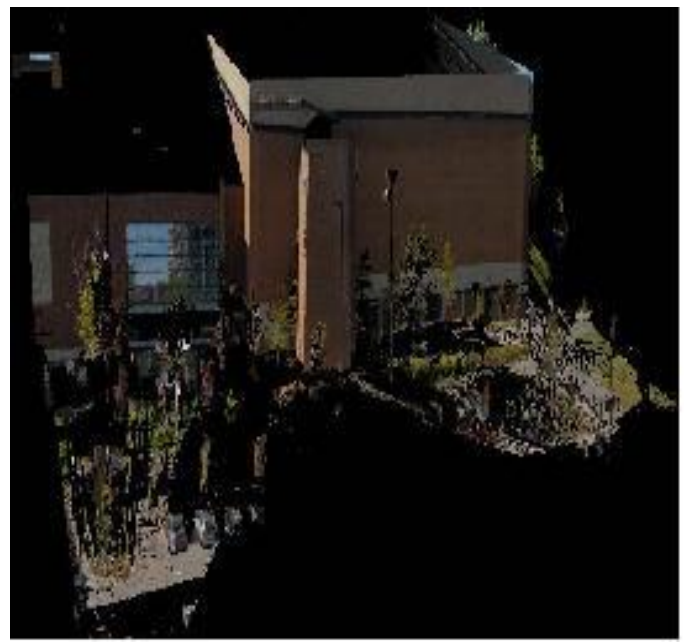

Fig.12. Textured point cloud model with laser and Images. (Source- Ming et al., 2009). 
3D City modeling by using Mobile Mapping System (MMS):

In 1989, the Center for Mapping of the Ohio State University established a major research program that focuses on the development of Mobile Mapping Systems (MMS). These devices capture a comprehensive set of land-related data from airplanes, cars, or trains. Spatial positions and attributes of objects are extracted automatically on the mobile platform or during post-processing, and are immediately transferred to a multi-media geographic database (Novak, 1995).

The University of Calgary and GEOFIT INC., a hightech company in Laval, Quebec, Canada have jointly developed the same system, The system named VISAT, stands for Video-Inertial-SATellite and integrates inertial and GPS technology with a cluster of CCD cameras.(El-Sheimy, 1996 \& Li , 1996).

Blaer and Allen, (2009), designed and developed a system for automatic view planning (Vue-Plan). They used Mobile robot and laser scanner for data capture to create a voxel based Next Best View (NBV), and create a final accurate and complete 3-D model. They also developed a simulator tool to test view planning algorithm on simulated sites. They successfully tested this work on to construct precise 3-D models of realworld sites located in New York City: Uris Hall on the campus of Columbia University and Fort Jay on Governors Island.

Pretto et al., (2010), designed a scalable dense 3D reconstruction and navigation system suitable for realtime operation. They successfully tested in a challenging urban scenario along a large loop using an Omni-directional camera mounted on the roof of a car.

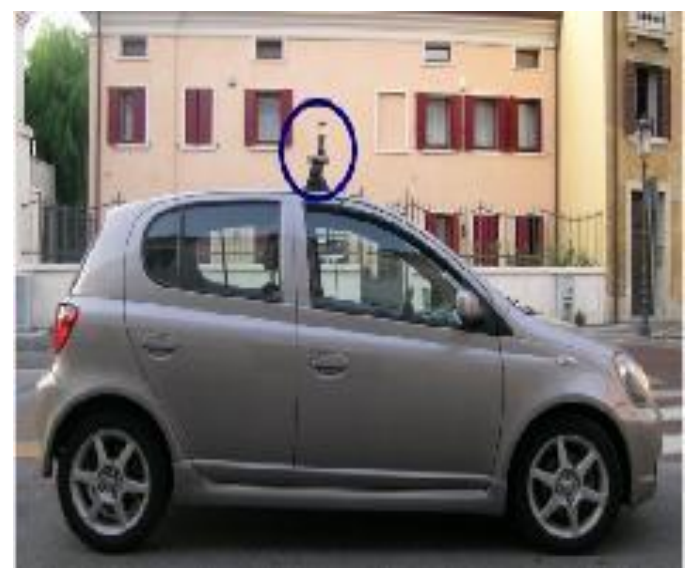

Fig.13. a) Vehicle with camera

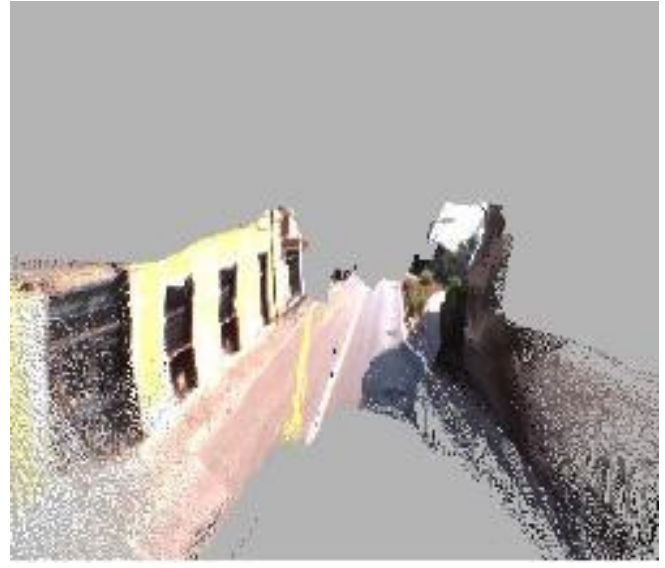

Fig.13. b) Dense 3D reconstruction

Imanishi, (2011), in Japan, they suggested a method for accuracy of MMS data at GPS invisible area. This Land Mark Update (LMU) technique, corrects MMS vehicle position using control points is employed to maintain accuracy. It is useful for MMS measurement data at GPS invisible area. This method is very useful and valid for tunnel mapping and/or very busy main road mapping where re-observation is difficult and it is usable to create road management map quickly and precisely.

In India, Bharat Lohani and his team, from IIT-Kanpur, Developed an Indigenous technique for Laser based Mobile mapping system for 3D modeling. It creates a basic and simple 3D model.

\section{HYBRID METHODS:}

\section{D City model by Aerial Laser and Terrestrial Laser:}

Böhm and Haala, (2005), developed a methodology for efficient integration of aerial and terrestrial laser data for virtual city modeling using LaserMaps. They used Leica HDS 3000 Terrestrial Laser scanner and TopScan's OPTECH ALTM 1225 Airborne Lidar. Terrestrial lasers scanning (TLS) used to collect building facades at a large amount of geometric detail, so the LaserMaps created from this methodology.

Visintini et al., (2007), recommended an approach to create 3-D City model of the area by matching historical maps with aerial and terrestrial surveying techniques. They used Optech ALTM 3033 system, and High- resolution Rollei DB44 digital images were also acquired for the same area. With the help of TerraScan (Terra Solid) software they create 3-D building model. For fecades generation, Laser scanner Riegle LMS Z360i system used and simultaneously digital images are also taken by Nikon D100 Camera.

Kurdi et al., (2007), also evaluated an approach for joint combination of point cloud and DSM for 3D building reconstruction using airborne laser scanner data. 
International Archives of the Photogrammetry, Remote Sensing and Spatial Information Sciences, Volume XL-2/W2, ISPRS 8th 3DGeolnfo Conference \& WG II/2 Workshop, 27 - 29 November 2013, Istanbul, Turkey

Combination of Laser and Photogrammetry based 3-D City Models:

\section{3-D City model by Airborne images and Lidar Data:}

Habib et al., (2008), proposed a methodology to create a realistic 3D city by integration of Lidar and Airborne imagery. They used lidar data for photogrammetric geo-referencing. They used Digital surface model and true ortho photos; to make the visualization more realistic, 3D symbols were added to the city model. They tested this work for campus of The University of Calgary. Arc Scene GIS software used for visualization and navigation of this result.

\section{3-D City model by Aerial Image and Ground Laser:}

Fruh and Zakhor, (2001), describe the techniques for 3-D textured model construction of any City using camera and laser scanner. They used a truck with one camera and two laser scanner travels on City Street under normal traffic condition. One horizontal and one vertical laser scanner used. They developed the methodologies which are based on Correlation techniques and Markov Carlo Localization. They used digital road maps and aerial photographs with laser scans and create a fairly accurate textured 3-D Model of area. In 2003, they also developed a textured 3D city model of Berkeley campus. (Fruh and Zakhor, 2003).

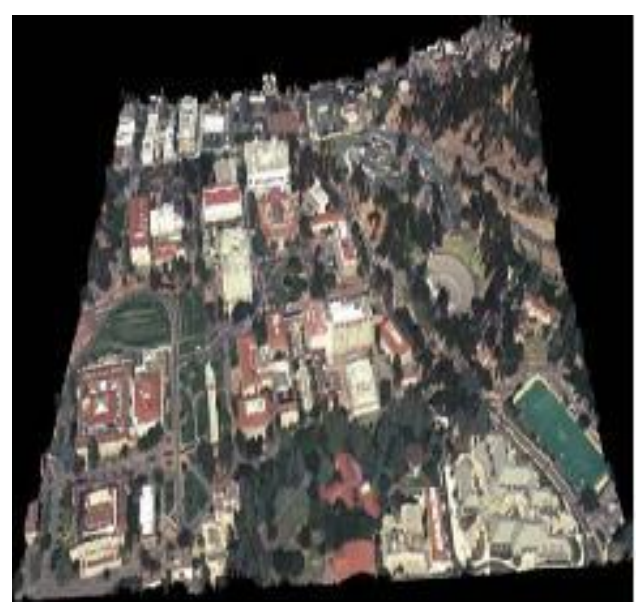

Fig.14- Texture mapped model of the Berkeley Campus (Source- Fruh and Zakhor, 2003).

\section{3-D City model by Aerial Laser and Ground Laser with} Aerial images and Ground Images:

Früh and Zakhor, (2003), developed and tested a methodology to construct 3-D City models by using Aerial and ground view. They used an Aerial laser and aerial images with ground laser and ground images. They create airborne model and façade model and give a final fused textured model of a city.

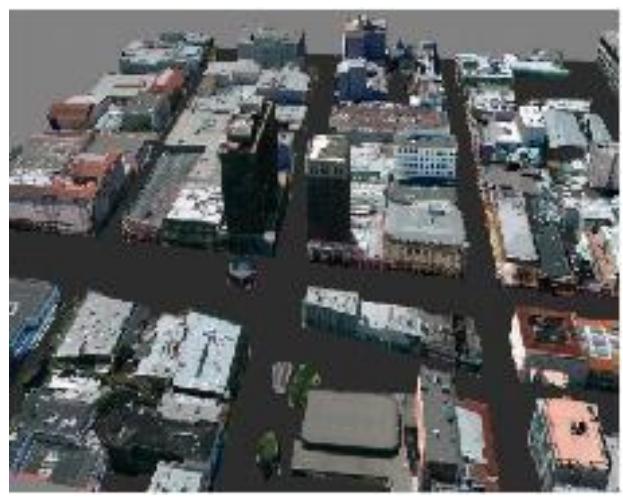

Fig.15- 3D model of area (source - Früh and Zakhor, 2003)

\section{ANN for 3-D City modeling:}

Yoshihiro Kobayashi, (2002), Arizona State University is used ANN for 3-D scene reconstruction. He developed 3D City Model Generator by using Neuro-Fuzzy concept in CAD. $\mathrm{He}$ introduces a computer-aided design (CAD) system in which a neuro-fuzzy system is integrated as a main engine for learning. Specifically, a computer system that generates 3D city models from satellite images is formulated, implemented, and tested. Techniques from neural networks, fuzzy systems, image processing, pattern recognition, and machine learning constitute the methodological foundation of the system. The usability and flexibility of the system are evaluated in case studies. The main purpose of this research is to develop a system that can automatically generate the 3D models from satellite images.

Juliana and Rodrigo, give the concept of Classification of Elements in a 3D Urban Virtual Environment using Artificial Neural Nets. In this work, with a good set of samples, the Multi Layer Perceptron (MLP) network is a good solution for objects classification for creating a $3 \mathrm{D}$ virtual city.

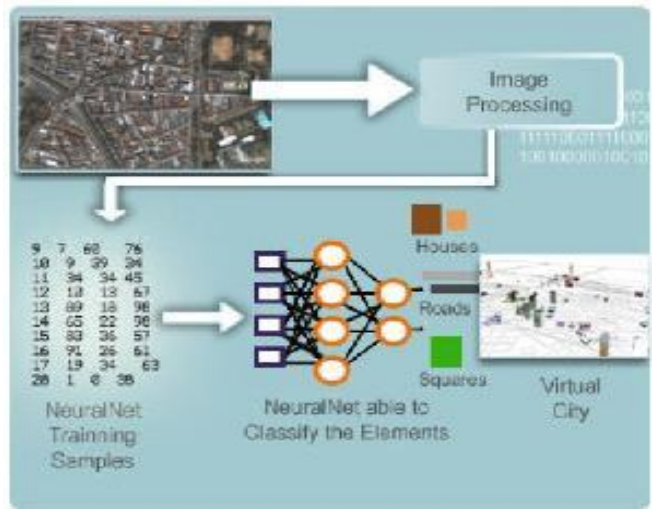

Fig. 16- Virtual 3-D City model generation by using ANN. (Source-Juliana and Rodrigo) 
Yoshihiro Kobayashi and Kostas Terzidis, (2000), also work with AA, ANN, and DIP. The main goal is to create a CAAD system that detects buildings from satellite images and produces computer city models allowing the system's users to manipulate the models utilizing machine learning technology. Soft computing technologies mainly neural networks and fuzzy systems are applied and tested as the system's methodology.

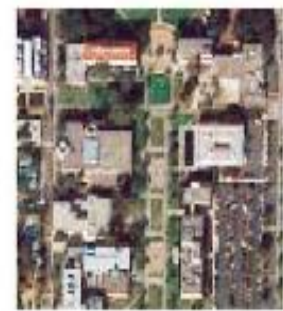

Sample Input Satellite Image

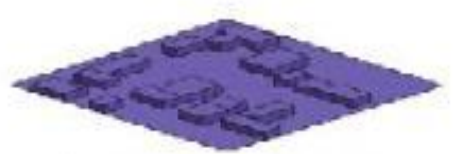

3D Cumputer City Mnile]

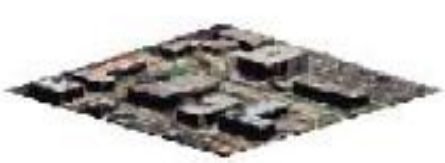

3D Computer City Model with Texture Mapping

Fig.17. Output Image of 3D Computer City (SourceKobayashi and Terzidis-2000)

\section{Video camera calibration for 3-D City modeling:}

In Japan, Kawasaki et al., (2004), Investigates and develop a methodology of Multiple Video Camera Calibration using Epipolar Plane Image (EPI) for City Modeling. This method enables simultaneous estimation of the multiple video cameras' parameters and the synchronization of video data. This method used to capture a large scale scene's texture image, a multiple video camera setup required to install on top of the car with no exacting configuration which take a video without using a special external synchronization device. In this method, they used by EPI-EPI matching method, and proposed the optical centers of the multiple cameras are made to coincide at one point in spatio-temporal space and thus these images fused into a single one with no distortions. No need for any overlapping areas between images for calibration, therefore large scale scene can be efficiently captured.

\section{Texture mapping for 3-D City modeling:}

Zhang et al., (2003), gives an effective approach and proposed a method for mapping the texture for building model based on the digital photogrammetric theory. They acquired the image sequences from digital video camera on helicopter and these images are used as texture resource. The experimental three-dimensional data result used for car navigation with good efficiency and good effect.

Frueh, et al., (2004), gives an approach to texture mapping a 3D city model obtained from aerial and ground-based laser scans with oblique aerial imagery. This work is evaluated on data set of Downtown Barkeley. In this work they automatically registered the images by matching $2 \mathrm{D}$ image lines with projections of 3D lines from the city model. For each triangle in the model, optimal image is selected by taking into account occlusion, image resolution, surface normal orientation, and coherence with neighboring triangles. At last, the utilized texture patches from all images are combined into one texture atlas for compact representation and efficient rendering.

Trapp et al., (2011), studied the Interactive Rendering Techniques for Highlighting in 3D Geovirtual Environments. 3D geovirtual environments (GeoVE), such as virtual 3D city and landscape models became an important tool for the visualization of geospatial information.

Highlighting is an important component for visualization framework. For 3D City Modeling, it has a number of applications, such as the visualization of user selections, data base queries, as well as navigation aid by highlighting way points, routes, or to guide the user attention.

\section{Web-based 3-D City models:}

Peng Chengzhi, (2005), developed SUCOD (Sheffield Urban Contextual Databank (SUCoD) system): It is a web-based platform for generating user defined 3-D City models. He also designed an experimental Web-based design environment called Townscaping to be used for architectural and urban design. In Townscaping, a set of tools is provided for users to create and edit 3D graphic elements to be positioned directly onto the user-specified virtual city models. The main key feature of Townscaping is to enable sketching while navigation. This study suggests that it is feasible for virtual city models to serve as interactive urban contexts for 3D sketch design. Townscaping is considered primarily a research platform for interacting and sketching with virtual townscapes.

Alexander Zipf, (2009), evaluated the concept of OpenSteetMap (OSM)-3D.

Over M., et al., (2010), investigates the prospects for the generation of interactive 3D City Models based on free geo-data available from the OpenStreet Map (OSM) project and height information provided by the Shuttle Radar Topography Mission. Web services were implemented to filter and display the data in an acceptable manner, follow the slandered specifications of the open geospatial consortium (OGC). 


\section{3-D City Model and CityGML:}

Kolbe Thomas H., (2005), explains about CityGML. City GML means City Geography Markup Language. It is an information model and GML application schema for the exchange of 3D city and landscape models. CityGML is a general information model for representing geovirtual 3D environments such as virtual $3 \mathrm{D}$ city models. It introduces classes and relations for topographic objects of urban environments and regional models.

CityGML mainly developed by the Special Interest Group 3D (SIG 3D) of the initiative Geo-data Infrastructure North-Rhine Westphalia, Germany (GDI NRW). And The international standardization was prepared by the CityGML Standard Working Group of the OGC with the support of EuroSDR. CityGML has now been adopted as an OGC.

The main key characteristic of CityGML is that it combines the ability to contain complex, georeferenced $3 \mathrm{D}$ vector data along with the semantics associated with the data. In contrast to other 3D vector formats, CityGML contains a rich, general purpose information model in addition to geometry and graphics content.

The CityGML information model includes:

- Digital Terrain Models as a combination of triangulated irregular networks (TINs), regular rasters, break and skeleton lines, mass points

- $\quad$ Sites (currently buildings and bridges)

- Vegetation (areas, volumes, and solitary objects with vegetation classification)

- Water bodies (volumes and surfaces)

- Transportation facilities (both graph structures and 3D surface data)

- City furniture

- Generic City objects and attributes

CityGML is complementary to $3 \mathrm{D}$ computer graphics standards like X3D, VRML, or COLLADA and geovisualization standards like KML.

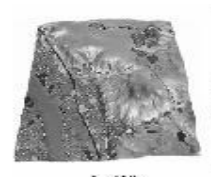

LoD'
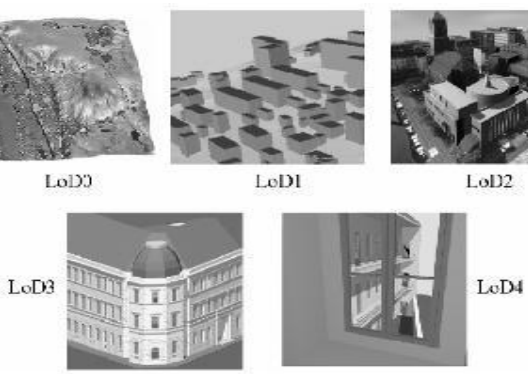

. Illustration of the five Levels-of-Detail iLODi defined by CituGML.

Fig.18. Lavels of Detail (LoD) defined by CityGML

CityGML provides a model at multiple levels of generalisation. These can be used individually within a model or multiple levels of representation can be modelled together. The levels are:
- $\quad$ LOD 0 - Regional, landscape

- $\quad$ LOD 1 - City, region

- $\quad$ LOD 2 - City districts, projects

- $\quad$ LOD 3 - Architectural models (exterior), landmarks

- $\quad$ LOD 4 - Architectural models (building interiors)

For specific domain areas, CityGML also provides an extension mechanism to allow the model to be enriched with additional properties and feature types. Targeted application areas explicitly include urban and landscape planning; architectural design; tourist and leisure activities; 3D cadastres; environmental simulations; mobile telecommunications; disaster management; homeland security; vehicle and pedestrian navigation; training simulators; and mobile robotics.

Franchin et al (2006) developed an Importer CityGML, a tool for parsing and importing CityGML datasets into a spatiotemporal database system. The system was developed in Java and uses classes and interfaces provided by XML Beans.

Kolbe et al., (2005), proposed a new model based on GML to describe data for any kind of city, CityGML is an open data model structure and standardized code based on XML for storing and exchanging virtual 3D city models.

Leonhard et al., (2007), explains about Metadata for 3D City Models. Metadata means the data describing data, it is known as structured data which describes and helps to find data sources.

This work is an analysis on the possibilities and deficiencies of current metadata standards as ISO19115 with respect to $3 \mathrm{D}$ city models.

CityGML is an open data model and XML-based format for the representation and exchange of virtual 3D city models. It is based on the Geography Markup Language version 3.1.1 (GML3). Both CityGML and GML3 are international standards issued by the Open Geospatial Consortium (OGC). CityGML not only represents the shape and graphical appearance of city models but specifically addresses the object semantics and the representation of the thematic properties, taxonomies and aggregations.

Alias et al., (2010), discusses the making of threedimensional geospatial data infrastructure (3D GDI) for Malaysia. They create a 3D City model and used the CityGML, texturing of facades via dynamic pulse function. In this modelling, they involve various aspects such as texturing, semantic and spatial database. They also introduced a novel method of texturing of building facades for 3D City models in CityServer3D environment. They also describes that how CityGML can be utilized for semantic modelling of the 3D modelling. This work was done for 3D Geospatial Data Infrastructure (3D SDI) framework for Putrajaya area of Malaysia. 
Mueller et al., (2007) gives a method for Image based procedural modeling of facades for 3D City modeling.

Backer T. et al., (2010) explain about Integrated 3D Modeling of multi-utility networks and their interdependencies for critical infra structure analysis.

Pawel B. and Christopher G., (2010) and Thab Hijazi et al., (2010) work for 3D modelling for interiors of buildings.

Mohamed El-Mekawy et al., (2010) explore the possibilities of CityGML and IFC modeling for 3D city. They proved that these strategies are very useful at the operational level (e.g., cost reduction, unified data-view), and at the strategic level (e.g., crisis management and increasing the analyses capabilities).

Leon and Ruben, (2010) explain about the integration of BIM and GIS. They describe the development of a CityGML extension called GeoBIM to get semantic IFC data into a GIS context.

L. Wang and Gunho Sohn, (2010), propose an integrated framework for the reconstruction of full 3D building models, in which both 3D indoor and outdoor model are reconstructed in a collaborative manner by fusing airborne laser scanning (ALS) data, terrestrial laser scanning (TLS) data and architectural plans. In this work, first, based on plane sweep technique, a semantic and geometric information integrated point matching based method is developed to register 2D floor plans with TLS points. And then based on the registration, 3D façade model and indoor model are reconstructed and integrated simultaneously

Qing Zhu et al., (2010) explain the semantic 3D city modelling based on CityGML and it's visual applications for GIS. In this work, they develop the interiors for Indoor navigation, Geological model for underground analysis for China. They also develop a semiautomatic data integration tool. They used data reduction and selective representation techniques for better visualization of model enriched by semantics.

A.Borrmann (2010) explores the use of Spatial Query Language (SQL) for BIM and 3D City Modeling. He develops a query language by using Metric operators (closerThan, fartherThan etc.), Directional operators (above, below, northOf etc.) and Topological operators (touch, within,contains etc.) for BIM and 3D city modeling.

D. Carrion et al. (2010) studied about estimation of the energetic rehabilitation state of building for the 3D city model of Berlin.

W.Wen et al., (2010) studied the energy consumption by using 3D city model. They discussed about dynamic features. They discuss a project called EnergyCity, developed by the Centre for 3D GeoInformation at Aalborg University. In this project, a 3D city model is enhanced into an energy system that allows politicians as well as citizens to visualize and understand the change of energy consumption and energy sources in an urban environment over a period of time.
I.A.Musliman et al., (2010) uses the 3D spatial operators with BIM in construction management using Geo-DBMS.

M.Uden and A.Zipf, (2013) explain about Open Building Models as a web platform for crowdsourcing Virtual 3D Cities. It is an approach for Volunteered Geographic Information (VGI) in 3D City modeling.

J.Stoler et al., (2012) explain the possibilities about Integrating scale and space in 3D City models.

B.Alsadik et al., (2012) designed a camera network for 3D modeling of cultural heritage objects.

\section{CONCLUSTION:}

Comparative statements of this research paper can be summarized in the following words: In the starting of computer era, the quality of 3D City model was not effective, but in present scenario, due to the advance techniques and algorithms, the real time web-based photo-textured, scalable and accurate 3D City modeling is possible.

Accuracy of 3D City model is depends on the scale of aerial images and is normally about 1:5000 with a forward and a side overlaps of 30 and 60 percent respectively. Using this data, many building details can be measured from the aerial images and the measurement error is maximal 0.2 meter in height. (Ulm, 2003).

The Hybrid methods are also gives good results. The combination of terrestrial close range images and aerial images are give a good solution, But in some country, the Arial flight is not allowed due to security purpose. The combination of terrestrial laser and Arial laser (ALTM) is also produced 3D City model of large area with in less time. The fusion of Laser and Photographs is also gives the best result for 3D City modeling.

Depends upon user requirements and available resources, any method can be used. Very High Resolution satellite images will also be very useful for the 3D City modeling.

Now a days, current trends is going for Laser scanning techniques, but this techniques also have some drawbacks like cost of equipments, point cloud data size, editing. Storing and management is also an important issue.

In some country like India, where aerial flight is restricted for mapping and modeling purpose. So in these cases: Close range photogrammeric method is most effective solution to create 3D City model. It gives better result and good accuracy.

Conclusion of this research paper is that, So many researchers are working for 3D City modeling, some are working for Techniques and some of them are working for Applications of 3D City modeling. Research is going on continuously to achieve more and more accuracy in less time with low cost of project, so these 3D City model can be used for various engineering and non-engineering purposes. 


\section{APPLICATIONS OF 3D CITY MODELS:}

The 3D city model can be created for a very wide range of purposes. These have been classified into twelve different categories of use (Batty $M$ et al. 2000):

- $\quad$ Emergency Services

- Urban Planning

- Telecommunications

- Architecture

- Facilities and utilities management

- Marketing and economic development

- analysis

- Tourism and entertainment

- E-commerce

- Environment

- Education and learning

- City portals.

These categories have been enhanced and grouped into four categories (Shiode 2001) as:

$>$ Planning and design,

$>$ Infrastructure and facility services,

$>$ Commercial sector and marketing,

$>$ Promotion and learning of information on cities.

Many researchers creates 3-D City model by using various techniques for various applications. The 3-D City model has a vast range of applications.

Level of Details (LoDs) is also an important criteria for specific kind of application.

3-D maps to real time web based virtual 3-D city model are used for various applications like planning, Navigation, tourism, environmental planning and analysis, for good e-governance etc are the main applications of virtual 3-D City models.

For applications of 3-D City models; the available literature can be summarized as given below-

Isikdag et al., (2008) studied about BIM for site selection and fire response management processes.

Schulze-Horsel, (2007), explains about the Potential applications of 3D city models. They marked these applications as given below:

$>$ City Planning

$>$ City Marketing

$>$ Civil Defense

$>$ Disaster Management

$>$ Energy Supply and Planning

$>$ Event Management

$>$ Environmental Management

$>$ Real Estate

$>$ Transportation/Navigation

$>$ Traffic Management

$>$ Virtual Tourism
Some of the major contribution is showing in the following table-

\begin{tabular}{|c|c|c|}
\hline Year & Authors & $\begin{array}{l}\text { Application of 3-D City } \\
\text { model for }\end{array}$ \\
\hline 1996 & Meister et al. & $\begin{array}{l}\text { CAAD supported analysis } \\
\text { and design of urban area }\end{array}$ \\
\hline 2000 & $\begin{array}{l}\text { G.Thomas \& S. } \\
\text { Donikrian }\end{array}$ & Behavioral animation \\
\hline 2002 & Ming et al. & CCTV Monitoring system \\
\hline 2004 & Li Chaokui et al. & $\begin{array}{l}\text { Spatial decision support } \\
\text { applications }\end{array}$ \\
\hline 2004 & Zhang et al. & $\begin{array}{l}\text { Spatial analysis to urban } \\
\text { design }\end{array}$ \\
\hline 2005 & Nakanishi et al. & $\begin{array}{l}\text { Real world crisis } \\
\text { management }\end{array}$ \\
\hline 2005 & Frank Bildstein & Simulation and training \\
\hline 2006 & Dollner Jurgen et al. & $\begin{array}{l}\text { As foundation of urban } \\
\text { spaces }\end{array}$ \\
\hline 2007 & $\begin{array}{l}\text { Vinay Kumar } \\
\text {.Kurukula }\end{array}$ & 3D Noise modeling \\
\hline 2007 & Slingsby \& Raper & $\begin{array}{l}\text { Navigable space analysis } \\
\text { for pedestrians }\end{array}$ \\
\hline 2007 & $\begin{array}{l}\text { M.Shashi \& Kamal } \\
\text { Jain }\end{array}$ & $\begin{array}{l}\text { Architectural } \\
\text { documentation }\end{array}$ \\
\hline 2008 & Sharkawi et al. & 3D Navigation system \\
\hline 2008 & $\begin{array}{l}\text { Markus Wolf and } \\
\text { Hartmut Asche }\end{array}$ & $\begin{array}{l}\text { Geospatial modeling of } \\
\text { urban security }\end{array}$ \\
\hline 2008 & Nurminen Antti & Mobile 3D City maps \\
\hline 2008 & Bradbury Joe & $\begin{array}{l}\text { Simulation and modeling } \\
\text { of Multipath and } \\
\text { availability of GNSS }\end{array}$ \\
\hline 2009 & Evan Stephens & $\begin{array}{l}\text { 3D cities and numerical } \\
\text { weather prediction models }\end{array}$ \\
\hline 2010 & Rose Lutz & Urban land management \\
\hline 2010 & Kapoor Mudit et al. & $\begin{array}{l}\text { Thermal analysis of } \\
\text { Building }\end{array}$ \\
\hline
\end{tabular}

This research paper may be incomplete for some point of view but it will give a good roadmap for other researcher who is working for 3D City modeling by using Geomatics techniques. 


\section{REFERENCES}

Al-Hanbali Nedal, Al Bayari Omar, Saleh Bassam, Almasri Husam and Baltsavias Emmanuel, 2006, "Macro to Micro Archaeological Documentation: Building a 3D GIS Model for Jerash City and the Artemis Temple", Innovations in 3D Geo-information systems, 447-468.

Al-Hanbali Nedal, Fedda Iyad, Awamleh Bashaar, and Dergham Mohannad, 2006, "Building 3D GIS Model of a University Campus for Planning Purposes: Methodology and Implementation aspects", Map Middle East, March 2629.

Alias Abdul-Rahman, Behnam Alizadehashrafi, Volker Coors, 2010, "Developing a framework for Malaysian 3D SDI", International Archives of the Photogrammetry, Remote Sensing and Spatial Information Sciences, Volume XXXVIII-4/W15. 5th International 3D GeoInfo Conference, November 3-4, Berlin, Germany.

A. Respaldiza, M. Wachowicz, A. Vázquez Hoehne, 2012, "Exploring cultural heritage resources in a 3D collaborative environment", International Archives of the Photogrammetry, Remote Sensing and Spatial Information Sciences, Volume XXXVIII-4/C26, 7th International Conference on 3D Geoinformation, May 16-17, , Québec, Canada.

A. Borrmann, 2010, "From GIS to BIM and back again- a spatial query language for 3-D Building models and 3-D City models", International Archives of the Photogrammetry, Remote Sensing and Spatial Information Sciences, Volume XXXVIII-4/W15, 5th International 3D GeoInfo Conference, November 3-4, Berlin, Germany.

Alexander Zipf, 2009, OpenStreetMap 3D: interoperable processing and visualization of high volume spatial data sets on the Web. GDI-3D, University of Bonn, Germany.

Antti Nurminen, 2008, "Mobile 3D city maps", IEEE Computer Graphics and Applications, Volume 28, Number 4, Pages-20-31.

Amat Nor'Ainah, Setan Halim and Majid Zulkepli, 2010, "Integration of aerial and close range Photogrammetric methods for 3D City modeling generation", Geoinformation Science Journal, Vol. 10, No. 1, 49-60.

Bashar Alsadik, Markus Gerke, George Vosselman, 2012, "Automated camera network design for 3D modeling of cultural heritage objects", Journal of Cultural Heritage, Elsevier publication.

Blaer Paul S. and Allen Peter K., 2009, "View Planning and Automated Data Acquisition for Three-Dimensional Modeling of Complex Sites", Journal of Field Robotics 26 (11-12), 865-891.

Böhm Jan, Haala Norbert, 2005, "Efficient integration of aerial and terrestrial laser data for virtual city modeling using LaserMaps", ISPRS WG III/3, III/4, V/3 Workshop "Laser scanning 2005", Enschede, the Netherlands, 12-14 September.
Becker, T., Nagel, C., Kolbe, T. H., 2010, "Integrated 3D Modeling of multi-utility networks and their interdependencies for critical infra structure analysis", International Archives of the Photogrammetry, Remote Sensing and Spatial Information Sciences, Volume XXXVIII-4/W15, 5th International 3D GeoInfo Conference, November 3-4, Berlin, Germany.

Clipp Brian, Raguram Rahul, Frahm Jan-Michael, Welch Gregory, Pollefeys Marc, 2008, "A Mobile 3D City Reconstruction System”, UNC Chapel Hill, ETH, Zurich.

Colleu Thomas, Sourimant Gaël, and Morin Luce, 2008, "Automatic Initialization for the Registration of GIS and Video Data", 3DTV, May, Istambul, Turkey.

Cornelis Nico, Leibe Bastian, Cornelis Kurt, Van Gool Luc, 2007, "3D Urban Scene Modeling Integrating Recognition and Reconstruction", International Journal of Computer Vision.

Cristina Portalés, José Luis Lerma, Santiago Navarro, 2010, "Augmented reality and Photogrammetry: A synergy to visualize physical and virtual city environments", ISPRS Journal of Photogrammetry and Remote Sensing 65, 134142.

Daniel Carrión , Alexandra Lorenz , Thomas H. Kolbe, 2010, "Estimation of the energetic rehabilitation state of buildings for the city of Berlin using a 3D City model represented in CityGML", International Archives of the Photogrammetry, Remote Sensing and Spatial Information Sciences, Volume XXXVIII-4/W15, 5th International 3D GeoInfo Conference, November 3-4, Berlin, Germany.

Dollner Jürgen, Baumann Konstantin, Buchholz Henrik, 2006, "Virtual 3D City Models as Foundation of Complex Urban Information Spaces", CORP 2006 \& Geomultimedia06. Vienna.

Döllner Jürgen, Kolbe Thomas H., Liecke Falko, Sgouros Takis, and Teichmann Karin, 2006, "The Virtual 3-D City model of Berlin- Managing, Integrating and Communicating complex urban information". Proceedings of the $25^{\text {th }}$ International symposium on Urban Data Management UDMS-2006, Aalborg, Denmark, 15-17 May.

Dorninger Peter and Pfeifer Norbert, 2008, “A Comprehensive Automated 3D Approach for Building Extraction, Reconstruction, and Regularization from Airborne Laser Scanning Point Clouds", Published in Sensors, 8, 7323-7343.

El-Sheimy, N., 1996, “A mobile Multi-Sensor System for GIS Applications in Urban Centers.”, International Archives of Photogrammetry and Remote Sensing, Vol. XXXI, Part B2, Vienna, July 9-19.

Eugster H. and Nebiker S., 2009, "Real time Georegistration of video stream from mini or micro UAS using Digital 3-D City models", 6th International Symposium on Mobile Mapping Technology, Presidente Prudente, São Paulo, Brazil, 21-24 July. 
Fangi G., 2009, "Further developments of the spherical Photogrammetry for culture heritage", $22^{\text {nd }}$ CIPA Symposium, October 11-15, Kyoto, Japan.

Flamanc D., Maillet G., Jibrini H., 2003, “3-D City models: an operational approach using aerial images and cadastral maps", ISPRS Archives, Vol. XXXIV, Part 3/W8, Munich, 17.-19.Sept.

Frank Bildstein. 2005, 3D City Models for Simulation \& Training. Workshop "Next Generation City Models", Bonn, 21-22 June.

Franchin Wagner, Carvalho Alexandre, Moreira Jose, Sousa A. Augusto de and Ribeiro Cristina, 2009, "An importer of virtual 3D City Models datasets into a spatiotemporal database", INForum'09, XML: Aplicacoes e Tecnologias Associadas, 326-330.

Fraser C.S., Baltsavias E., Gruen A., 2002, "Processing of Ikonos imagery for sub metre 3D positioning and building extraction", ISPRS Journal of Photogrammetry \& Remote Sensing 56, 177- 194.

Frueh Christian, Sammon Russell, and Zakhor Avideh, 2004, "Automated Texture Mapping of 3.D City Models With Oblique Aerial Imagery", In 3D Data Processing, Visualization and Transmission, 3DPVT 2004. Proceedings, 2nd International Symposium on IEEE, 396-403.

Fruh Christian and Zakhor Avidesh, 2001, "3-D Model generation for cities using aerial photographs and ground lavel scans". IEEE.

Fruh Christian and Zakhor Avidesh, 2003, "Constructing 3D City Models by Merging Ground-Based and Airborne Views". Published by the IEEE Computer Society, November/December.

Fulton J.R. and Fraser C.S., 2009, "Automated Reconstruction of Buildings using a Hand Held Video Camera", S. Jones, K. Reinke (eds.), Innovations in Remote Sensing and Photogrammetry, Lecture Notes in Geoinformation and Cartography, Springer-Verlag Berlin Heidelberg, 393-404.

Gwenola Thomas and Stéphane Donikian, 2000, "Modelling virtual cities dedicated to behavioural animation" EUROGRAPHICS, Volume 19 Number 3

Gael Sourimant, Luce Morin,Kadi Bouatouch, 2007, “GPS, GIS and Video fusion for urban modeling". CGI, May.

Gruen Armin and Xinhua Wang, 1999, "3-D Urban mapping for a hybrid GIS", Proc. of workshop "Urban 3D/Multi-Media Mapping", September, Tokyo, Japan, 6978.

Gruen Armin, Li Zhang, Wang Xinhua, 2003, "3D City Modeling with TLS (Three-Line Scanner) Data", International Archives of the Photogrammetry, Remote Sensing and Spatial Information Sciences, Vol. XXXIV5/W10, 24-27.

Gruen, A., Wang, X., 1998, "CC Modeler: A Topology Generator for 3-D City Models", ISPRS Commission IV
Symposium on "GIS - Between vision and application", Stuttgart/Germany, IAPRS. Vol. 32, Part 4, 188-196.

Gruin, A., Wang, X., 1999, "CyberCity Modeler: a tool for interactive 3- D city model generation", Photogrammetric week, Wichmann, Karlsruhe.

Habib A. F., Kersting J., McCaffrey T. M., Jarvis A. M. Y., 2008, "Integration of Lidar and airborne imagery for realistic visualization of 3D urban environments", The International Archives of the Photogrammetry, Remote Sensing and Spatial Information Sciences. Vol. XXXVII. Part B2, Beijing.

Hammoudi Karim and Dornaika Fadi, 2011, “A Featureless Approach to 3D Polyhedral Building Modeling from Aerial Images", Sensors, 11, 228-259.

Hengel Anton van den, Dick Anthony, Thormahlen Thorsten, Ward Ben, Philip H, and Torr S., 2007, "VideoTrace: Rapid interactive scene modelling from video", In ACM Transactions on Graphics, Vol. 26, No. 3, 86.

Hideyuki Nakanishi, Satoshi Koizumi, Toru Ishida. 2005, "Virtual Cities for Real-World Crisis Management. P. van den Besselaar and S. Koizumi (Eds.): Digital Cities 2003, LNCS 3081, Pages- 204-216,

Herraez Jose, Coll Eloina, Martinez Jose-Carlos, 2001, "Epipolar Frames in a Line for Videogrammetry", Engineering in Cartography, Geodesy and Photogrammetry, Polytecnic University of Valencia, Spain.

Huang Xiaojing, Kwoh Leong Keong, 2008, "Monoplotting- A semi-automated approach for 3-D reconstruction from single satellite image", The International Archives of the Photogrammetry, Remote Sensing and Spatial Information Sciences. Vol. XXXVII, Part B3b. Beijing.

Ivin Amri Musliman, Alias Abdul-Rahman, and Volker Coors, 2010, "Incorporating 3D Spatial Operator with building information models in construction management using Geo-DBMS", International Archives of the Photogrammetry, Remote Sensing and Spatial Information Sciences, Volume XXXVIII-4/W15, 5th International 3D GeoInfo Conference, November 3-4, Berlin, Germany.

Imanishi Akihisa, Tachibana Kikuo and Tsukahara Koichi, 2011, "The Development of Accuracy Maintenance Method for Mobile Mapping System (MMS) Data at GPS Invisible Area", FIG Working Week, Bridging the Gap between Cultures Marrakech, Morocco, 18-22, May.

Ihab Hijazi, Manfred Ehlers, Sisi Zlatanova , Thomas Becker, Léon van Berlo, 2010, "Initial investigations for modeling interior utilities with in 3D geo context: Transforming IFC-Interior utility to CityGML/ Utility networkade", International Archives of the Photogrammetry, Remote Sensing and Spatial Information Sciences, Volume XXXVIII-4/W15, 5th International 3D GeoInfo Conference, November 3-4, Berlin, Germany.

Isikdag U., Towards the Implementation of Building Information Models in Geospatial Context, $\mathrm{PhD}$ Thesis, University of Salford, UK, 2006. 
Isikdag U., Underwood J., Aouad G. 2008, “An investigation into the applicability of building information models in geospatial environment in support of site selection and fire response management processes". Journal of Advanced Engineering Informatics, 22 (4), pp. 504-519.

Izadi Mohammad, and Saeedi Parvaneh, 2012, "ThreeDimensional Polygonal Building Model Estimation From Single Satellite Images", IEEE Transactions on Geoscience and Remote sensing Vol. 50, NO. 6, June, 2254-2272.

Jang Kyung Ho and Jung Soon Ki, 2006, "3D City Model Generation from Ground Images”, Eds.: H.P. Seidel, T. Nishita, and Q. Peng, CGI 2006, Springer-Verlag Berlin Heidelberg. LNCS 4035, 630-638.

Jürgen DÖLLNER, Konstantin BAUMANN, Henrik BUCHHOLZ, 2006, "Virtual 3D City Models as Foundation of Complex Urban Information Spaces", CORP 2006 \& Geomultimedia06. Vienna.

Jianxiong Xiao, Tian Fang, Peng Zhao, Maxime Lhuillier, Long Quan, 2009, "Image-based Street-side City Modeling", SIGGRAPH ASIA.

Joe Bradbury, 2008, "The Integration of City Models and GNSS for the Simulation and Modelling of Multipath and Availability: Paving the Way for New Applications", PhD Thesis, Department of Civil, Environmental and Geomatic Engineering, University College London.

J.Stoler et al., (2012) explain the possibilities about Integrating scale and space in 3D City models.

Jantien Stoter, Hugo Ledoux , Martijn Meijers, Ken Arroyo Ohori, 2012, "Integrating scale and space in 3D city models", International Archives of the Photogrammetry, Remote Sensing and Spatial Information Sciences, Volume XXXVIII-4/C26, 7th International Conference on 3D Geoinformation, May 16-17, , Québec, Canada.

Kawasaki Hiroshi, Atsunori Miyamoto, Yutaka Ohsawa, Shintaro Ono and Katsushi Ikeuchi, 2004, "Multiple video camera calibration using EPI for city modeling", In Proc. Asian Conf. on Computer Vision, vol. 1, 569-574.

Kapoor, Mudit, Khreim, Jean-Francois, El Meouche, Rani, Bassir, David, Henry, Anne Laure, Ghosh, Sanjay K, 2010, "Comparison of techniques for the 3D modeling and thermal analysis", APEGA 2010, Graphic Expression applied to Building, International Conference. Pages- 163173.

Kawasaki Hiroshi, Yatabe Tomoyuki, Ikeuchi Katsushi, Sakauchi Masao, 1999, "Automatic Modeling of a 3D City Map from Real-World Video", Institute of Industrial Science, University of Tokyo, Japan.

K.H. Sharkawi, M.U. Ujang and A. Abdul-Rahman, 2008, "3D Navigation system for virtual reality based on 3D Game engine", The International Archives of the Photogrammetry, Remote Sensing and Spatial Information Sciences. Vol. XXXVII. Part B4. Beijing. Pages- 513-518.

Kobayashi Y., 2006, "Photogrammetry and 3-D City modelling”, Digital Arch, School of Architecture and landscape Architecture, Arizona State University, USA.
Kocaman S., Zhang L., Gruen A., Poli D., 2006, “3-D City modeling from high resolution satellite images", Proc. of the ISPRS Conference Topographic Mapping from Space (With Special Emphasis on Small Satellites).

Kolbe T., Groger G., and Plumer L., 2005, "Interoperable Access to 3D City Models", First International Symposium on Geo-Information for Disaster Management, Springer, Delft, Netherlands, 21-23 March.

Kurdi, F. Tarsha, T. Landes, P. Grussenmeyer, 2007, "Joint combination of point cloud and DSM for 3D building reconstruction using airborne laser scanner data", published in 4th IEEE GRSS, Paris, France.

Kolbe Thomas H., 2009, "Representing and Exchanging 3D City Models with City GML". 3D Geo-information Sciences, 15-31.

Lang Felicitas, Forstner Wolfgang, 1996, "3-D City modeling with a digital one-eye stereo system", International Archives of Photogrammetry and Remote Sensing, 261-266.

Li, R., et al., 1996. “ Mobile Mapping for 3D GIS Data Acquisition" International Archives of Photogrammetry and Remote Sensing, Vol. XXXI, Part B2, Vienna, July 9-19.

Li Chaokui, Zhu Qing, Zhang Yeting, Huang Duo, Zhao Jie, Chen Songlin, 2004, "Spatial Decision Support Applications Based on Three-Dimensional City Models" Geo-spatial Information Science (Quarterly), Volume 7, Issue 2, 135-143.

Leberel F., Irschara A., Pock T., Meixner P., Gruber M., Scholz S., and Wiechert A., 2010, "Point Clouds: Lidar versus 3D Vision", Photogrammetric Engineering \& Remote Sensing Vol. 76, No. 10, October, 123-1134.

Léon van Berlo, Ruben de Laat, 2010, "Integration of BIM and GIS: The development of the CityGML GeoBIM Extension", International Archives of the Photogrammetry, Remote Sensing and Spatial Information Sciences, Volume XXXVIII-4/W15, 5th International 3D GeoInfo Conference, November 3-4, Berlin, Germany.

Langyue Wang and Gunho Sohn, 2010, "An Integrated framework for reconstructing full 3D building models", International Archives of the Photogrammetry, Remote Sensing and Spatial Information Sciences, Volume XXXVIII-4/W15, 5th International 3D GeoInfo Conference, November 3-4, Berlin, Germany.

Luhmann Thomas, and Tecklenburg Werner, 2004, "3-D Object reconstruction from multiple-station panorama imagery", International Archives of the Photogrammetry, Remote Sensing and Spatial Information Sciences 34, No. 5/W16: 8.

Lutz Ross, 2010, "Virtual 3D City Models in Urban Land Management: Technologies and Applications" PhD Thesis, Institute of Geodesy and Geo-Information Science at the Technical University of Berlin. Berlin.

Leonhard Dietze, Ulrike Nonn, Alexander Zipf, 2007, "Metadata for 3D City Models- Analysis of the Applicability of the ISO 19115 Standard and Possibilities 
for further Amendments", 10th AGILE International Conference on Geographic Information Science, Aalborg University, Denmark.

M.Uden and A.Zipf, 2013, explain about Open Building Models as a web platform for crowdsourcing Virtual 3D Cities. It is an approach for Volunteered Geographic Information (VGI) in 3D City modeling.

Markus Wolff and Hartmut Asche, 2008, "Geospatial Modelling of Urban Security: A Novel Approach with Virtual 3D City Models", O. Gervasi et al. (Eds.): ICCSA 2008, Part I, LNCS 5072, Pages. 42-51.

Mal J. Sahlin, M. A. Mostafavi, A. Forest, M. Babin, B. Lansard, 2012, "3D geospatial modelling and visualization for marine environment: Study of the marine pelagic ecosystem of the south-eastern Beaufort Sea, Canadian Arctic", International Archives of the Photogrammetry, Remote Sensing and Spatial Information Sciences, Volume XXXVIII-4/C26, 7th International Conference on 3D Geoinformation, May 16-17, , Québec, Canada.

Umpong Chayakrit, and Chen Xiaoyong, 2008, "Interoperable 3-Dimentional GIS City modelling with Geoinformatics techniques and 3-D modeling software", The International Archives of the Photogrammetry Remote sensing and Spatial information sciences, Vol. XXXVII, Part B, Beijing.

Meister M. Sinning, Gruen A., Dan H., 1996, "3D City models for CAAD-supported analysis and design of urban areas", ISPRS Journal of Photogrammetry \& Remote Sensing ,51, 196-208

Mohamed El-Mekawy, Anders Östman and Khurram Shahzad, 2010, "Towards interoperating CityGML and IFC building model based approach", International Archives of the Photogrammetry, Remote Sensing and Spatial Information Sciences, Volume XXXVIII-4/W15, 5th International 3D GeoInfo Conference, November 3-4, Berlin, Germany.

Micusık Branislav, Kosecka Jana, 2009, "Piecewise Planar City 3D Modeling from Street View Panoramic Sequences", IEEE.

Mueller, P., Zeng, G., Wonka, P., Van Gool, L., 2007, "Image-Based Procedural Modeling of Facades", ACM Trans. Graph. 26, 3, Article 85 (July 2007), 9 pages.

Ming J. Li-Chee, Gumerov D., Ciobanu T., Armenakis C., 2009, "Generation of Three Dimensional Photo-Realistic Models from Lidar and Image Data", IEEE-TIC-STH.

Ming Ying, Jiang Jingjue, Bian Fulin, 2002, "3-D City model supporting for CCTV monitoring system" ISPRS, Wuhan University", China.

Novak, K., 1993, "Mobile mapping systems: new tools for the fast collection of GIS information". In Optical Engineering and Photonics in Aerospace Sensing, International Society for Optics and Photonics, October, 188-198.
Over M., Schilling A., Neubauer S., Zipf A., 2010, "Generating web-based 3D City Models from OpenStreetMap: The current situation in Germany", Computers, Environment and Urban Systems 34, 496-507.

Paul Rajesh, Subramanian Siva, and Bharadwaj Shalabh, 2006, "Creation of Digital City Models Using Single High Resolution Satellite Image", Photogrammetric Engineering and Remote sensing, April, 341-342.

Pawel Boguslawski, Christopher Gold, 2010, "Rapid modelling of complex building interiors", International Archives of the Photogrammetry, Remote Sensing and Spatial Information Sciences, Volume XXXVIII-4/W15, 5th International 3D GeoInfo Conference, November 3-4, Berlin, Germany.

Peng Chengzhi, 2005, "Townscaping: Development of Dynamic Virtual City Augmented 3D Sketch Design Tools", B. Martens and A. Brown (eds.), Computer Aided Architectural Design Futures, 105-114.

Pollefeys M., Koch R., Vergauwen M., Van Gool L., 2000, "Automated reconstruction of 3D scenes from sequences of images", ISPRS Journal of Photogrammetry \& Remote Sensing 55, 251-267.

Pollefeys M., Nistér D., Frahm J.M., Akbarzadeh A., Mordohai P., Clipp B., Engels C., Gallup D., Kim S.J., Merrell P., Salmi C., Sinha S., Talton B., Wang L., Yang Q., Stewénius H., Yang R., Welch G., Towles H., 2008, "Detailed Real-Time Urban 3D Reconstruction from Video", International Journal of Computer Vision, 78: 143-167.

Pollefeys Marc, Gool Luc Van, Vergauwen, Maarten, Cornelis Kurt, Verbiest Frank, Tops Jan, 2002, "Video-to3D", International Archives of Photogrammetry, Remote sensing and Spatial Information Sciences. 34(3/A), 252-257.

Pretto Alberto, Soatto Stefano, and Menegatti Emanuele, 2010, "Scalable Dense Large-Scale Mapping and Navigation", Proceedings of the $2^{\text {nd }}$. Workshop on Omnidirectional Robot Vision, A workshop of the IEEE, International Conference on Robotics and Automation (ICRA2010), Anchorage, Alaska, USA, May 7, 49-56.

Püschel Hannes, Sauerbier Martin, Eisenbeiss Henri, 2008, "A 3-D Model of castle landenberg $(\mathrm{CH})$ from combined photogrammetric processing of terrestrial and UAV based images", International Archives of the Photogrammetry, Remote Sensing and Spatial Information Sciences, 37, 9398.

Qing Zhu, Junqiao Zhao, Zhiqiang Du, Yeting Zhang, Weiping Xu, Xiao Xie, Yulin Ding, Fei Wang and Tingsong Wang, 2010, "Towards semantic 3D City modeling and visual explorations", ", International Archives of the Photogrammetry, Remote Sensing and Spatial Information Sciences, Volume XXXVIII-4/W15, 5th International 3D GeoInfo Conference, November 3-4, Berlin, Germany.

Razzak Abdul, Ziboon T., and Mohsin Amjed N., 2009, “3D Virtual Maps Production for Mosul City by using GIS Techniques", Eng. \& Tech. Journal, Vol. 27, No.9. 
Remondino, Fabio, and Sabry El-Hakim., 2006, "Image based 3D Modelling: A Review", The Photogrammetric Record, 21, 115, 269-291.

Shashi M. and Jain Kamal, 2007, "Use of Photogrammetry in 3D Modeling and visualization of buildings", Asian Research Publishing Network (ARPN) - Journal of Engineering and Applied Sciences. Vol. 2, No. 2, April, ISSN 1819-6608.

Snavely Noah, Seitz Steven M., and Szeliski Richard, 2008, "Modeling the World from Internet Photo Collections", International Journal of Computer Vision, 80,189-210.

Slingsby, A. and Raper, J., 2007, "Navigable Space in 3D City Models for Pedestrians", Advances in 3D Geoinformation Systems, (Peter van Oosterom, Sisi Zlatanova, Friso Penninga and Elfriede M. Fendel, Eds.), pp. 49-64, Springer Berlin Heidelberg,

Stephen Evans, 2009, "3D cities and numerical weather prediction models: An overview of the methods used in the LUCID project", Working paper series, Paper 148, Centre for Advanced Spatial Analysis University College London

Tack F., Goossens R., Buyuksalih G., 2009, "Semi automatic city model extraction from tri-streoscopic VHR satellite imagery", In: Stilla U, Rottensteiner F, Paparoditis N (Eds) CMRT09. IAPRS, Vol. XXXVIII, Part 3/W4, Paris, France, 3-4 September.

Tao C. Vincent and Hu Yong, 2002, "3D Reconstruction methods based on Rational Function Model", Photogrammetric Engineering and Remote Sensing Vol. 68, No. 7, July, 705-714.

Thompson Emine Mine and Horne Margaret, 2009, “3DGIS Integration for Virtual NewcastleGateshead", School of Built Environment, University of Northumbria, England.

Tian Yixiang, Gerke Markus, Vosselman George, and Zhu Qing, 2010, "Knowledge-based building reconstruction from terrestrial video sequence", ISPRS Journal of Photogrammetry and Remote Sensing, 65, 395-408.

Trapp Matthias, Beesk Christian, Pasewaldt Sebastian, Dollner Jurgen, 2011, "Interactive Rendering Techniques for Highlighting in 3D Geovirtual Environments", Advances in 3D Geo-Information Sciences, 197-210.

Tsai Fuan, Chen Cheng-Hsuan, Liu Jin-Kim and Hsiao Kuo-Hsing, 2006, "Texture Generation and Mapping Using Video Sequences for 3D Building Models", Innovations in 3D Geo Information Systems, 429-438.

Ulm K., 2003. Improved 3D City Modeling With Cybercity- Modeler (Cc-Modeler ${ }^{\mathrm{TM}}$ ) Using Aerial-, Satellite Imagery And Laserscanner Data, International Archives of the Photogrammetry, Remote Sensing and Spatial Information, Sciences, Vol. XXXIV-5/W 10

Vinay kumar Kurakula, 2007, "A GIS-Based Approach for 3D Noise Modelling Using 3D City Models", MSc Thesis, International Institute for Geo-Information Science and Earth Observation, Enschede, The Netherlands
Visintini D., Guerra F., Adami A., Vernie P., 2007, “A 3D Virtual model of the Gorizia downtown (Italy) by matching historical maps with aerial and terrestrial surveying techniques", e-Perimetron, Vol. 2, No. 3, 117-133.

Vosselman George and Dijkman Sander, 2001, "3D building model reconstruction from point clouds and ground plan", International Archives of Photogrammetry and Remote Sensing, Volume XXXIV-3/W4 Annapolis, MD, 22-24 Oct.

W. Wen, E. Kjems, L. Bodum, J. Kolar, 2010, "Dynamic features in a 3D City model as an energy system", International Archives of the Photogrammetry, Remote Sensing and Spatial Information Sciences, Volume XXXVIII-4/W15, 5th International 3D GeoInfo Conference, November 3-4, Berlin, Germany.

Yoshihiro Kobayashi and Kostas Terzidis, 2000, "Extracting the Geometry of Buildings from Satellite Images Using Fuzzy Multiple Layer Perceptrons".

Yoshihiro Kobayashi, 2002, "3D City Model Generator: The Application of Neuro-Fuzzy Systems in CAD", Arizona State University, USA.

Zhang Guofeng, Jia Jiaya, Wong Tien-Tsin, and Bao Hujun, 2009, "Consistent Depth Maps Recovery from a Video Sequence, IEEE Transactions on pattern analysis and machine intelligence, June, Vol. 31, No. 6, 974-988.

Zhang Zuxun, Wu Jun, Zhang Jianqing, 2003, "Rapid Texture Mapping from Image Sequences for Building Geometry Model", Geo spatial Information Science (Quarterly) Vol. 6, Issue 3, September, 8-15.

Zhao W., Nister D., and Hsu S., 2005, "Alignment of Continuous Video onto 3D Point Clouds", Pattern Analysis and Machine Intelligence, IEEE Transactions on 27 Aug., 1305-1318.

Zhou Li, Sun Jia-long, Li Wei-xiao, Bai He, and Chen Weiwei, 2008, "The study on the techniques of the 3-D GIS modeling based on the digital Photogrammetry", The International Archives of the Photogrammetry, Remote Sensing and Spatial Information Sciences. Vol. XXXVII, Part B, Beijing.

Zhang Xia, Zhu Qing and Wang Jingwen, 2004, "3-D City models based spatial analysis to urban design" Geographic Information Sciences, Volume 10, No.1, Pages- 82-86.

Zlatanova S., Paintsil J., Tempfli K., 1998,“3D Object reconstruction from aerial stereo images", In Proceeding of the 6th international conference in Central Europe on computer graphics and visualization, Vol. 98, 472-478. 